Published in final edited form as:

Atherosclerosis. 2008 October ; 200(2): 345-349. doi:10.1016/j.atherosclerosis.2007.11.014.

\title{
Assessment of pre- and post-methionine load homocysteine for prediction of recurrent stroke and coronary artery disease in the Vitamin Intervention for Stroke Prevention Trial
}

\author{
Luther C. Pettigrew, M.D., Heejung Bang, Ph.D., Lloyd E. Chambless, Ph.D., Virginia J. \\ Howard, M.S.P.H., James F. Toole, M.D., and the VISP Investigators \\ Stroke Program, Sanders-Brown Center on Aging, and Department of Neurology, University of \\ Kentucky College of Medicine, Lexington, Kentucky (L.C.P.), Division of Biostatistics and \\ Epidemiology, Department of Public Health, Weill Medical College, Cornell University, New York, \\ New York (H.B.), Department of Biostatistics, Collaborative Studies Coordinating Center, \\ University of North Carolina, Chapel Hill, North Carolina (L.E.C.), Department of Epidemiology, \\ University of Alabama at Birmingham, Birmingham, Alabama (V.J.H.), and Stroke Research \\ Center, Department of Neurology, Wake Forest University School of Medicine, Winston-Salem, \\ North Carolina (J.F.T.)
}

\begin{abstract}
Methionine (Met) loading increases total plasma homocysteine (tHcy) and assesses homocysteine metabolism. We tested the hypothesis that pre- or post-Met tHcy will predict recurrent stroke or coronary artery disease (CAD) in a subgroup analysis of the Vitamin Intervention for Stroke Prevention (VISP) trial. VISP subjects with non-disabling stroke underwent measurement of tHcy at baseline (fasting pre- and post-Met load) and were randomized to high/low-dose B-vitamin therapy for prevention of recurrent stroke or CAD. In the sample cohort of 2,124 subjects, mean \pm SD tHcy levels in $\mu \mathrm{mol} / \mathrm{L}$ were: pre-Met 13.2 \pm 4.3 , post-Met $30.4 \pm 9.76$, and pre/post-Met $\Delta$ $17.1 \pm 8.3$. The hazard ratio (HR) for recurrent stroke was $1.16(p=0.026)$ for 1 SD higher pre-Met tHcy and $1.15(p=0.054)$ for 1 SD higher post-Met tHcy. For CAD, the HR for 1 SD higher preMet tHcy was $1.27(p=0.001)$ and was $1.00(p=0.99)$ for post-Met tHcy. In survival analyses using pre- or post-Met as covariates, the coefficient of pre/post-Met $\Delta$ was not significant for stroke and was only marginally significant for $\mathrm{CAD}(p<0.08)$, but was negative. We conclude that fasting, pre-Met tHcy is as effective as post-Met tHcy or pre/post-Met $\Delta$ in predicting the risk for stroke and CAD.
\end{abstract}

\section{Keywords}

Homocyst(e)ine; Methionine; Vitamins; Stroke; Myocardial Infarction

(C) 2007 Elsevier Ireland Ltd. All rights reserved.

Address correspondence and requests for reprints to: L. Creed Pettigrew, M.D., M.P.H., Stroke Program, Sanders-Brown Center on Aging, University of Kentucky College of Medicine, 101 Sanders-Brown Building, 800 South Limestone Street, Lexington, Kentucky 40536-0230, Office telephone: (859) 257-5560, Facsimile transmission: (859) 257-8990, E-mail address: cpetti@uky.edu.

Publisher's Disclaimer: This is a PDF file of an unedited manuscript that has been accepted for publication. As a service to our customers we are providing this early version of the manuscript. The manuscript will undergo copyediting, typesetting, and review of the resulting proof before it is published in its final citable form. Please note that during the production process errors may be discovered which could affect the content, and all legal disclaimers that apply to the journal pertain. 


\section{Introduction}

Homocysteine is a sulfhydryl amino acid product of methionine metabolism. Case-control studies performed in subjects with moderate hyperhomocysteinemia show that elevated homocysteine, obtained after fasting or methionine loading, is an independent risk factor for premature coronary artery disease (CAD), stroke, or peripheral vascular disease resulting from atherosclerosis. 1, 2 Mechanisms by which homocysteine may cause occlusive vascular disease in the heart and brain include increased propensity for thrombosis, impaired thrombolysis, increased production of hydrogen peroxide, endothelial dysfunction, and increased oxidation of low-density lipoprotein. $3^{-5}$

To identify hyperhomocysteinemia more sensitively, oral loading with methionine has been used to determine the content of acid-soluble homocysteine that is present only in low concentrations in fasting plasma. In a cohort drawn from the NHLBI Family Heart Study, $57 \%$ of hyperhomocysteinemic individuals were identified from tHcy levels obtained after fasting and before methionine loading. 6 The remaining $43 \%$ required assay of tHcy after methionine loading or calculation of the difference between pre- and post-load levels. In a case-control study of tHcy as a predictor of vascular disease risk examined within the European Concerted Action Project, Graham and colleagues found that reliance only on fasting tHcy classified $27 \%$ fewer patients as hyperhomocysteinemic. 7

Recognizing that methionine loading is reported to more accurately define hyperhomocysteinemia, we evaluated the comparative utility of tHcy sampled after fasting or methionine loading and by calculation of the pre-post load difference in tHcy for prediction of symptomatic atherothrombotic disease. We examined tHcy levels obtained before or after methionine loading in patients with non-disabling cerebral infarction (NDCI) who were enrolled in the Vitamin Intervention for Stroke Prevention (VISP) clinical trial. In this subgroup analysis of VISP, we tested the hypothesis that tHcy assayed only after fasting will be equivalent to the level obtained after methionine loading or by pre-post load difference in tHcy for prediction of recurrent stroke or symptomatic CAD.

\section{Subjects and Methods}

The rationale, design, and results of the VISP trial have been published.8, 9 Briefly, VISP was a randomized, prospective, double-masked, multi-center clinical trial of secondary stroke prevention that compared high- to low-dose B-vitamin therapy. The primary outcome measure was recurrent stroke. Secondary outcome measures included symptomatic CAD and all-cause death. Screening samples for quantification of plasma tHcy were obtained from patients recruited within 120 days of a qualifying NDCI. If shown to be eligible by a screening tHcy level that exceeded $25^{\text {th }}$ percentile for a benchmark population, the subject would be scheduled for a randomization visit during which tHcy levels were obtained before and after a methionine loading test.

Methionine loading was performed as described in our original report.8 Each subject was fasted overnight and a sample of whole blood for tHcy assay was obtained before the methionine load (pre-Met). The subject was then given methionine $(0.1 \mathrm{~g} / \mathrm{kg}$ body weight $)$ as a crystalline powder dissolved in $227 \mathrm{ml}$ ( 8 ounces) of unsweetened fruit juice. Two hours after the methionine load, a second whole blood sample was obtained for postmethionine load (post-Met) tHcy. The absolute difference between pre- and post-methionine load tHcy was also calculated (pre/post-Met $\Delta$ ).

Each whole blood specimen for tHcy analysis was drawn in duplicate, using vacutainer tubes containing EDTA that were light-sealed and centrifuged to prepare plasma aliquots for assay by high-performance liquid chromatography (HPLC).10-12 For quality control, 
replicate plasma aliquots were obtained from a sample of study participants $(\mathrm{n}=283)$ and sent to the central laboratory with different identifiers. The inter-run coefficient of variation for tHcy was 0.08 and the correlation between repeat measurements of blind replicates was 0.94 .8

To identify variables associated with pre/post-Met $\Delta$, we used Pearson correlation coefficients for univariate association and multiple linear regression models for joint association. The associations between two different tHcy variables and survival outcomes such as recurrent stroke and CAD were modeled by the Cox proportional hazard regression model after adjusting for key covariates at baseline (i.e., vitamin dose, age, sex, and race). In this model, pre/post-Met $\Delta$ was added to see if the new marker increased predictability of outcome. We also implemented the Receiver Operating Characteristic (ROC) curve and calculated the area under the curve (AUC) in order to assess the diagnostic properties of key tHcy variables. The AUCs of the indices were compared using a non-parametric method.13 We used SAS software, version 8 (SAS Institute Inc., Cary, NC) for all statistical analyses. Two-sided hypotheses were adopted for statistical inference.

\section{Results}

After excluding subjects with insufficient fasting time ( $<8$ hours) or missing pre- or postMet tHcy levels $(n=1,550)$ and others with extreme tHcy levels, pre-Met tHcy $>50 \mu \mathrm{mol} / \mathrm{L}$ or post-Met tHcy $>80 \mu \mathrm{mol} / \mathrm{L}$, that were suspected to be outliers $(\mathrm{n}=6), 2,124$ patients remained in the sample cohort drawn from the entire VISP population. Within this cohort, 166 subjects had recurrent stroke (7.8\%) during their participation in VISP and 123 had symptomatic CAD (5.8\%). In the intention-to-treat population randomized for the VISP trial $(\mathrm{n}=3,680), 300$ subjects had a recurrent stroke $(8.2 \%)$ and 237 had symptomatic CAD (6.4\%). Table 1 presents summary statistics for key baseline characteristics of the sample cohort in comparison to the VISP population.

In this sample cohort drawn from the VISP population, mean \pm standard deviation (SD) tHcy levels in $\mu \mathrm{mol} / \mathrm{L}$ were: pre-Met 13.2 \pm 4.3 , post-Met $30.4 \pm 9.76$, and pre/post-Met $\Delta$ $17.1 \pm 8.3$. We found that pre/post-Met $\Delta$ correlated strongly with post-Met tHcy, but weakly with pre- Met tHcy. The Pearson correlation coefficient between pre/post-Met $\Delta$ and post-Met tHcy was 0.87 but was only 0.11 with pre-Met tHcy $(p<0.0001)$. The correlation coefficient between pre-and post-Met tHcy was stronger at $0.56(p<0.0001)$.

To evaluate the association between pre/post-Met $\Delta$ and pre-specified prognostic factors, we considered pre-Met tHcy, some important demographic variables (age, sex and race), and randomly assigned treatment, as listed in Table 2. A standard multiple linear regression model was adopted for this analysis. It was shown that pre-Met tHcy and pre/post-Met $\Delta$ were positively associated in the multiple linear regression model. We found that pre/postMet $\Delta$ increases were smaller in older subjects $(0.12 \mu \mathrm{mol} / \mathrm{L}$ lower per year of age $)$ but were larger in women than in men (by $5.1 \mu \mathrm{mol} / \mathrm{L}$ ) and in whites than in blacks (by $4.6 \mu \mathrm{mol} / \mathrm{L}$ ), all of which were highly significant $(p<0.0001)$.

Next, the assumption of proportionality of hazards was tested and the use of the Cox model was justified.14 Hazard ratios (HRs) for recurrent stroke or symptomatic CAD, as calculated in survival analysis models using pre- or post-Met tHcy as the predictive variable, are shown in Table 3. The HR for recurrent stroke was $1.16(p=0.026)$ for $1 \mathrm{SD}$ higher pre-Met tHcy and 1.15 ( $p=0.054)$ for 1 SD higher post-Met tHcy. For CAD, the HR associated with 1 SD higher pre-Met tHcy was $1.27(p=0.001)$ and was $0.998(p=0.985)$ for 1 SD higher post-Met tHcy. The effect of pre/post-Met $\Delta$, without accounting for individual tHcy, was not statistically significant for either endpoint. The HR of pre/post-Met $\Delta$ was significantly 
different from the null when added to the survival model using pre-Met tHcy to predict CAD $(p=0.027)$, but showed some protective effects. When added to the model using pre-Met tHcy to predict recurrent stroke, it was not significant. Since post-Met and pre/post-Met $\Delta$ are highly correlated, they were not included jointly in any regression analysis. The HRs shown in Table 3 correspond to a 1-standard deviation increase of the respective factor (preor post-Met load or pre/post-Met $\Delta$ considered singly), assuming other conditions remain fixed. In all other cases, the HRs were examined under conditions that permitted two dependent factors (e.g., pre-Met and pre/post-Met $\Delta$ ) to be varied jointly.

Table 4 summarizes the results from the ROC/AUC analysis. It is notable that pre-Met tHcy improves the risk predictability of each cardiovascular outcome beyond the key baseline factors $(p=0.05)$, unlike post-Met tHcy. However, an increased predictive ability by the additional use of pre/post-Met $\Delta$ information is only borne out in prediction of symptomatic $\mathrm{CAD}(p=0.03)$.

We attempted to correct the HRs for potential measurement errors in tHcy using reliability coefficients obtained from Tsai and co-workers.15 Although VISP was not designed to assess the statistical implications of tHcy measurement errors, some sense of the potential impact of this error may be obtained through externally applied reliability coefficients. After this correction, pre-Met tHcy showed an increase in HR of $7-10 \%$ while the increase in HR observed with post-Met tHcy did not exceed 3\%, as applied to prediction of either recurrent stroke or symptomatic CAD.

\section{Discussion}

The most important finding in this subgroup analysis of the VISP trial is that pre-Met tHcy was comparable to post-Met or pre/post-Met $\Delta$ in predicting risk of both recurrent stroke and symptomatic CAD. In predicting recurrent stroke, we found that elevation of fasting, pre-Met tHcy above $1 \mathrm{SD}$ was the most effective prognosticator among the variables that we examined, that the same threshold in post-Met tHcy was less sensitive (as shown by less stringent $p$ value in HR calculation on survival analysis), and that pre/post-Met $\Delta$ was ineffective. For predicting symptomatic CAD, elevation of pre-Met tHcy was strongly associated with increased risk, although the same threshold in post-Met tHcy was insignificant. Addition of pre/post-Met $\Delta$ in multivariate regression models predicting symptomatic CAD was statistically significant, although with protective effects. The role of pre/post-Met $\Delta$ was meaningful only when considered together with pre-Met value; the associations with the outcome became stronger and prediction was improved. Our analysis suggests that pre-Met tHcy is the most powerful and effective predictor of CAD risk, as it is for recurrent stroke, that post-Met tHcy is not predictive, and that pre/post-Met $\Delta$ may be more useful in prediction of CAD than of stroke. These conclusions are strengthened by deriving qualitatively similar risk profiles for both stroke and CAD from two different statistical techniques (i.e., survival and ROC analyses).

We recognize that observations drawn from this subgroup analysis may be limited by its evaluation of a cohort group defined within the original VISP population.16, 17

Furthermore, it is possible that the statistical power of this study could be influenced by lack of subject compliance with study treatment in VISP or incomplete acquisition of data in an extended, longitudinal trial.18 However, our use of this approach is strengthened by adherence to guidelines recommended for valid subgroup analyses of clinical trials.19 It is important to note that we did not conduct standard multivariate regression modeling (with comprehensive adjustment for covariates) to identify novel risk factors or to duplicate validation of thcy as an independent risk factor for cardiovascular disease.1, 2 Our goal in this subgroup analysis was to compare and evaluate the relative importance of pre and post- 
Met tHcy for prediction of two major outcomes of the VISP trial, recurrent stroke and CAD. In following this approach, we chose minimally-adjusted statistical models (focused on cohort demographics and treatment assignment only) and employed standard techniques such as proportional hazards modeling and ROC analysis to strengthen and simplify our conclusions.

As shown in Table 1, there was relatively symmetric clustering of both pre- and post-Met tHcy between the sample cohort and the base population in VISP, although the two differed by several characteristics and did not have uniform fasting times (12 hours for the sample cohort and 8 hours for the base population in VISP). The baseline cobalamin level was lower in the sample cohort than in the VISP population, but both remained well above thresholds defining cobalamin deficiency in routine clinical practice and in the VISP trial.8 Overall, the magnitude of these statistically significant differences remained limited, thereby suggesting that the cohort was representative of all subjects enrolled in VISP.

Variability in tHcy levels may be caused by unfavorable lifestyle factors, renal insufficiency, concomitant use of phenytoin, and dietary supplementation with B-vitamins, 20 all of which were controlled or excluded in the VISP clinical trial. Post-Met tHcy may be heavily influenced by polymorphisms in the human gene for methylenetetrahydrofolate reductase (MTHFR), the folate-dependent enzyme that converts approximately $50 \%$ of circulating homocysteine into methionine. In a large study of tHcy levels assayed before and after methionine loading in 51 Dutch pedigrees, the 677C $>$ T MTHFR genotype accounted for $67.5 \%$ of post-Met tHcy heritability (genetically explained variance/total variance) but had no effect on fasting tHcy.21 Although MTHFR genotyping was not performed in VISP, we excluded patients with pre-Met tHcy $>50 \mu \mathrm{mol} / \mathrm{L}$ or Post-Met tHcy $>80 \mu \mathrm{mol} / \mathrm{L}$ as outliers who could harbor undiscovered MTHFR polymorphisms.

This study describes the largest reported cohort of individuals in which fasting, pre-Met tHcy has been compared to post-Met tHcy and pre/post-Met $\Delta$ for stratification of atherothrombotic risk. We conclude that fasting tHcy without Met loading is comparable to post-Met tHcy or pre/post-Met $\Delta$ for prediction of recurrent stroke and CAD in high-risk patients with hyperhomocysteinemia. We propose that fasting thcy be quantified routinely for stratification of vascular risk in patients with mild stroke or transient ischemic attack.

\section{Acknowledgments}

Financial support for this study was provided by grants awarded from the National Institutes of Health to Wake Forest University for the Vitamin Intervention for Stroke Prevention Trial(NINDS R01 NS34447) and to the University of Kentucky (General Clinical Research Center; M01RR02602). The participation of one co-author, Heejung Bang, Ph.D., was supported partially by the Tolly Vinik Trust through Weill Medical College of Cornell University.

\section{References}

1. Boers GH, Smals AG, Trijbels FJ, Fowler B, Bakkeren JA, Schoonderwaldt HC, Kleijer WJ, Kloppenborg PW. Heterozygosity for homocystinuria in premature peripheral and cerebral occlusive arterial disease. N Engl J Med. 1985; 313:709-715. [PubMed: 4033695]

2. Clarke R, Daly L, Robinson K, Naughten E, Cahalane S, Fowler B, Graham I. Hyperhomocysteinemia: an independent risk factor for vascular disease. N Engl J Med. 1991; 324:1149-1155. [PubMed: 2011158]

3. Chambers JC, McGregor A, Jean-Marie J, Obeid OA, Kooner JS. Demonstration of rapid onset vascular endothelial dysfunction after hyperhomocysteinemia: an effect reversible with vitamin C therapy. Circulation. 1999; 99:1156-1160. [PubMed: 10069782] 
4. Leerink CB, van Ham AD, Heeres A, Duif PF, Bouma BN, van Rijn HJ. Sulfhydryl compounds influence immunoreactivity, structure and functional aspects of lipoprotein(a). Thromb. Res. 1994; 74:219-232. [PubMed: 8042190]

5. Stamler JS, Slivka A. Biological chemistry of thiols in the vasculature and in vascular-related disease. Nutr Rev. 1996; 54:1-30. [PubMed: 8919695]

6. Bostom AG, Jacques PF, Nadeau MR, Williams RR, Ellison RC, Selhub J. Post-methionine load hyperhomocysteinemia in persons with normal fasting total plasma homocysteine: initial results from the NHLBI Family Heart Study. Atherosclerosis. 1995; 116:147-151. [PubMed: 7488329]

7. Graham IM, Daly LE, Refsum HM, Robinson K, Brattstrom LE, Ueland PM, Palma-Reis RJ, Boers GH, Sheahan RG, Israelsson B, Uiterwaal CS, Meleady R, McMaster D, Verhoef P, Witteman J, Rubba P, Bellet H, Wautrecht JC, de Valk HW, Sales Luis AC, Parrot-Rouland FM, Tan KS, Higgins I, Garcon D, Medrano MJ, Candito M, Evans AE, Andria G. Plasma homocysteine as a risk factor for vascular disease. The European Concerted Action Project. JAMA. 1997; 277:1775-1781. [PubMed: 9178790]

8. Toole JF, Malinow MR, Chambless LE, Spence JD, Pettigrew LC, Howard VJ, Sides EG, Wang $\mathrm{CH}$, Stampfer M. Lowering homocysteine in patients with ischemic stroke to prevent recurrent stroke, myocardial infarction, and death: the Vitamin Intervention for Stroke Prevention (VISP) randomized controlled trial. JAMA. 2004; 291:565-575. [PubMed: 14762035]

9. Spence JD, Howard VJ, Chambless LE, Malinow MR, Pettigrew LC, Stampfer M, Toole JF. Vitamin Intervention for Stroke Prevention (VISP) Trial: rationale and design. Neuroepidemiology. 2001; 20:16-25. [PubMed: 11174041]

10. Malinow MR, Sexton G, Averbuch M, Grossman M, Wilson MS, Upson B. Homocyst(e)inemia in daily practice: levels in coronary artery disease. Coron. Art. Dis. 1990; 1:215-220.

11. Malinow MR, Kang SS, Taylor LM, Wong PW, Coull B, Inahara T, Mukerjee D, Sexton G, Upson B. Prevalence of hyperhomocyst(e)inemia in patients with peripheral arterial occlusive disease. Circulation. 1989; 79:1180-1188. [PubMed: 2785871]

12. Smolin LA, Schneider JA. Measurement of total plasma cysteamine using highperformance liquid chromatography with electrochemical detection. Anal Biochem. 1988; 168:374-379. [PubMed: 3364734]

13. DeLong ER, DeLong DM, Clarke-Pearson DL. Comparing the areas under two or more correlated receiver operating characteristic curves: a nonparametric approach. Biometrics. 1988; 44:837-845. [PubMed: 3203132]

14. Hosmer, DW., Jr; Lemeshow, S. Applied Survival Analysis: Regression Modeling of Time to Event Data. New York: Wiley; 1999. p. 386

15. Tsai MY, McGovern P, Kennedy EL, Hanson NQ. Short-term variability in the measurement of plasma homocysteine, fasting and post-methionine loading. Clin Biochem. 2001; 34:49-52. [PubMed: 11239515]

16. Assmann SF, Pocock SJ, Enos LE, Kasten LE. Subgroup analysis and other (mis)uses of baseline data in clinical trials. Lancet. 2000; 355:1064-1069. [PubMed: 10744093]

17. Burgess DC, Gebski VJ, Keech AC. Baseline data in clinical trials. Med J Aust. 2003; 179:105107. [PubMed: 12864724]

18. Yusuf S, Wittes J, Probstfield J, Tyroler HA. Analysis and interpretation of treatment effects in subgroups of patients in randomized clinical trials. JAMA. 1991; 266:93-98. [PubMed: 2046134]

19. Cook DI, Gebski VJ, Keech AC. Subgroup analysis in clinical trials. Med J Aust. 2004; 180:289291. [PubMed: 15012568]

20. De Bree A, Verschuren WM, Kromhout D, Kluijtmans LA, Blom HJ. Homocysteine determinants and the evidence to what extent homocysteine determines the risk of coronary heart disease. Pharmacological reviews. 2002; 54:599-618. [PubMed: 12429870]

21. den Heijer M, Graafsma S, Lee SY, van Landeghem B, Kluijtmans L, Verhoef P, Beaty TH, Blom H. Homocysteine levels--before and after methionine loading--in 51 Dutch families. Eur J Hum Genet. 2005; 13:753-762. [PubMed: 15756298] 


\section{Table 1}

Comparison of Baseline Characteristics and Endpoints between the VISP Population and a Sample Cohort Selected for Prediction of Stroke and Coronary Artery Disease (CAD) Risk from Homocysteine Levels with or without Methionine Loading

\begin{tabular}{|c|c|c|c|}
\hline & All VISP Participants ( $N=3,680)$ & $\begin{array}{c}\text { Sample Cohort for Prediction of Stroke and Coronary Artery } \\
\text { Disease Risk }(\mathbf{N}=\mathbf{2 , 1 2 4})\end{array}$ & $p$-value ${ }^{*}$ \\
\hline Age (years) & $66.3 \pm 10.8$ & $66.1 \pm 10.9$ & 0.097 \\
\hline \multicolumn{4}{|l|}{ Sex } \\
\hline Male & $2,301(62.5 \%)$ & $1,373(64.6 \%)$ & \multirow[t]{2}{*}{0.002} \\
\hline Female & $1,379(37.5 \%)$ & $751(35.4 \%)$ & \\
\hline \multicolumn{4}{|l|}{ Race } \\
\hline White & $2,925(79.5 \%)$ & $1,713(80.7 \%)$ & \multirow[t]{3}{*}{0.067} \\
\hline Black & $545(14.8 \%)$ & $290(13.7 \%)$ & \\
\hline Other races & $210(5.7 \%)$ & $121(5.7 \%)$ & \\
\hline \multicolumn{4}{|l|}{ Cholesterol level (mg/dl) } \\
\hline Total & $201.9 \pm 46.7$ & $203.1 \pm 46.0$ & 0.07 \\
\hline LDL & $122.3 \pm 40.1$ & $123.9 \pm 39.7$ & 0.007 \\
\hline HDL & $45.4 \pm 15.5$ & $45.9 \pm 15.8$ & 0.026 \\
\hline \multicolumn{4}{|l|}{ Blood pressure $(\mathrm{mm} \mathrm{Hg})$} \\
\hline SBP & $140.8 \pm 18.7$ & $140.6 \pm 18.5$ & 0.38 \\
\hline DBP & $77.9 \pm 10.1$ & $78.1 \pm 9.8$ & 0.21 \\
\hline $\mathrm{B}_{12}(\mathrm{ng} / \mathrm{ml})$ & $361.5 \pm 228.5$ & $351.5 \pm 205$ & 0.002 \\
\hline Pre-Met tHcy $(\mu \mathrm{mol} / \mathrm{L})$ & $13.4 \pm 5.1$ & $13.2 \pm 4.3$ & 0.012 \\
\hline Post-Met tHcy ( $\mu \mathrm{mol} / \mathrm{L})$ & $29.8 \pm 10.4$ & $30.4 \pm 9.8$ & $<0.001$ \\
\hline Pre/post-Met $\Delta$ & $16.5 \pm 8.9$ & $17.2 \pm 8.3$ & $<0.001$ \\
\hline Smoking & $621(16.9 \%)$ & $391(18.4 \%)$ & 0.004 \\
\hline Recurrent Stroke & $300(8.2 \%)$ & $166(7.8 \%)$ & $* *$ \\
\hline Coronary Artery Disease & $237(6.4 \%)$ & $123(5.8 \%)$ & $* *$ \\
\hline \multicolumn{4}{|c|}{$\begin{array}{l}* \\
p \text {-value for testing the difference of each factor between the subjects included vs. the subjects excluded in the analysis. The } t \text {-test for continuous } \\
\text { variables and the chi-square test for categorical variables were adopted for } p \text { value calculation. }\end{array}$} \\
\hline
\end{tabular}


Table 2

Variables Associated with Pre/Post-Methionine Difference $(\Delta)$ in Total Plasma Homocysteine (tHcy) Using a Multiple Linear Regression Model

\begin{tabular}{lcc}
\hline & Estimate (Standard Error) & $\boldsymbol{p}$-value \\
\hline Pre-Met tHcy $(\mu \mathrm{mol} / \mathrm{L})$ & $0.27(0.03)$ & $<.0001$ \\
Treatment $\left(\mathrm{H} \mathrm{vs.}^{1}\right)$ & $0.35(0.34)$ & 0.30 \\
Age (1 year increase) & $-0.12(0.02)$ & $<.0001$ \\
Sex (women vs. men) & $5.08(0.36)$ & $<.0001$ \\
Race (black vs. white) & $-4.59(0.50)$ & $<.0001$ \\
\hline
\end{tabular}

${ }^{1}$ H vs. L: High- vs. low-dose B vitamins in VISP formulation 
Table 3

Hazard Ratios ${ }^{1}$ for Recurrent Stroke or Symptomatic Coronary Artery Disease as Predicted by Total Plasma Homocysteine before or after Methionine Loading

\begin{tabular}{|c|c|c|c|c|}
\hline \multirow[b]{2}{*}{ Sample of Total Plasma Homocysteine } & \multicolumn{2}{|l|}{ Stroke } & \multicolumn{2}{|c|}{ Coronary Artery Disease } \\
\hline & Hazard Ratio (95\% C.I.) & $p$-Value & Hazard Ratio (95\% C.I.) & $p$-Value \\
\hline Pre-Methionine Load & $1.16(1.02,1.33)$ & 0.026 & $1.27(1.10,1.46)$ & 0.001 \\
\hline Post-Methionine Load & $1.15(1.00,1.33)$ & 0.054 & $1.00(0.83,1.20)$ & 0.985 \\
\hline Pre/Post-Met $\Delta$ & $1.09(0.94,1.28)$ & 0.254 & $0.83(0.67,1.02)$ & 0.077 \\
\hline Pre-Methionine Load ${ }^{2}$ & $1.15(1.01,1.32)$ & 0.041 & $1.30(1.12,1.49)$ & 0.0004 \\
\hline Pre/post-Met $\Delta^{2}$ & $1.07(0.91,1.24)$ & 0.427 & $0.79(0.64,0.97)$ & 0.027 \\
\hline \multicolumn{5}{|c|}{$\begin{array}{l}1 \text { Hazard ratios were computed from a Cox proportional hazard regression model, adjusting for treatment group, age, sex, and race and corresponc } \\
\text { to } 1 \text { standard deviation increase (i.e., } 4.3 \text { for Pre-Met; } 9.8 \text { for Post-Met; } 8.3 \text { for Pre/post-Met } \Delta \text { ). }\end{array}$} \\
\hline
\end{tabular}




\section{Table 4}

Diagnostic Characteristics for Predicting Endpoints (Recurrent Stroke and Coronary Artery Disease) in Sequentially Constructed Models

\begin{tabular}{lllll}
\hline & \multicolumn{2}{c}{ Stroke } & \multicolumn{2}{c}{ Coronary Artery Disease } \\
\cline { 2 - 5 } Model $^{1}$ & $\mathbf{A U C}^{2}$ & p-value $^{3}$ & AUC $^{2}$ & p-value $^{3}$ \\
\hline Model 1 & 0.557 & & 0.620 & \\
Model 2 & 0.575 & 0.23 & 0.648 & 0.05 \\
Model 3 & 0.563 & 0.67 & 0.621 & 0.45 \\
Model 4 & 0.573 & 0.38 & 0.658 & 0.03 \\
Model 5 & 0.573 & 0.38 & 0.658 & 0.03 \\
\hline
\end{tabular}

1 Model 1 is a baseline model with the covariates of treatment, age, sex and race;

Model 2 is Model 1, additionally adjusting Pre-Met tHcy;

Model 3 is Model 1, additionally adjusting Post-Met tHcy;

Model 4 is Model 1, additionally adjusting Pre-Met tHcy and Pre/post-Met $\Delta$;

Model 5 is Model 1, additionally adjusting Post-Met tHcy and Pre/post-Met $\Delta$.

2

2 AUC: Area under ROC Curve

3

p-value for testing if there is a significant AUC improvement by using the given model, compared to model 1 . 